\title{
The Solution-State Conformations of 2,4,6-Tri-t-butyl-benzaldehyde and -thiobenzaldehyde
}

\author{
Henri Lumbroso and Jacqueline Curé \\ Laboratoire de Chimie Générale, Université Pierre et Marie Curie, Paris, France
}

Renzo Okazaki, Akihiko Ishii, and Naoki Inamoto

Department of Chemistry, Faculty of Science, The University of Tokyo, Japan*

Z. Naturforsch. 40 a, 1157-1161 (1985); received June 24, 1985

Formyl-ring conjugation has been examined in benzaldehyde, 2,4,6-trimethyl- and 2,4,6-tri$t$-butyl-benzaldehyde, and the ab initio STO-3G $\pi$-electron distribution in benzaldehyde has been analysed in terms of the mesomeric and $\pi$-inductive effect of the formyl group. The electric dipole moment determined in benzene solution at $30.0^{\circ} \mathrm{C}$, and formyl-carbon n.m.r. chemical shift, recorded in deuterochloroform, of 2,4,6-tri-t-butylbenzaldehyde indicate a nonplanar conformation with a formyl-group rotational angle $(\varphi)$ of about $65^{\circ}$. The dipole moment of 2,4,6-tri$t$-butylthiobenzaldehyde, also in benzene solution at $30.0^{\circ} \mathrm{C}$, is consistent with a nearly orthogonal model $\left(\varphi \sim 90^{\circ}\right)$, in agreement with the X-ray structure in the crystalline phase giving $\varphi=89.1^{\circ}$.

\section{Introduction}

Unlike 2,4,6-trimethylbenzaldehyde, which has been examined by ultraviolet spectroscopy [1], dipole moment and electric birefringence techniques [2], dielectric dispersion methods [3], and ${ }^{1} \mathrm{H}$ and ${ }^{13} \mathrm{C}$ spin-lattice relaxation techniques [4], more overcrowded 2,4,6-tri-t-butylbenzaldehyde has only been examined by ${ }^{1} \mathrm{H}$ n.m.r. spectroscopy [5]. 2,4,6-Tri- $t$-butylthiobenzaldehyde, the first example of a stable thiobenzaldehyde isolated without resort to stabilization by heteroatoms, has been recently prepared by Okazaki and co-workers [6], and its Xray structure has been determined in the crystalline phase [7].

In the present work, the electric dipole moments of 2,4,6-tri- $t$-butyl-benzaldehyde and -thiobenzaldehyde have been determined in benzene at $30.0^{\circ} \mathrm{C}$, with the aim of elucidating their conformations in solution.

\section{Experimental}

\section{Synthetic}

2,4,6-Tri-t-butylbenzaldehyde. - 2,4,6-Tri-t-butylbromobenzene $(8.12 \mathrm{~g}, 25.0 \mathrm{mmol})$ in $100 \mathrm{ml}$ of tetra-

* Bunkyo-ku, Tokyo 113.

Reprint requests to Prof. Dr. H. Lumbroso, Laboratoire de Chimie Générale, Université Pierre et Marie Curie, 4, place Jussieu, 75252 Paris Cédex 05, France. hydrofuran was allowed to react with $n$-butyllithium ( $30 \mathrm{mmol}$ ) in hexane at $-78^{\circ} \mathrm{C}$ for ten minutes, and to this solution was added dropwise ethyl formate $(5.6 \mathrm{ml}, 69 \mathrm{mmol})$. Then the temperature was gradually raised to room temperature, and after stirring for an additional hour the solution was quenched with aqueous ammonium chloride, the solvent evaporated and the residue extracted with dichloromethane. The extract was dried with anhydrous magnesium sulphate and the residue obtained after evaporation of the solvent was chromatographed on silica-gel (hexane-ether 30:1) to give 2,4,6-tri-t-butylbenzaldehyde $(3.23 \mathrm{~g}$, yield $47 \%$ ), m.p. $197.5-198.5^{\circ} \mathrm{C}$ (from methanol); ${ }^{1} \mathrm{H}$ n.m.r. spectrum $\left(\mathrm{CDCl}_{3}\right): \delta$ (p.p.m.) $1.32(9 \mathrm{H}, \mathrm{s})$, $1.36(18 \mathrm{H}, \mathrm{s}), 7.37(2 \mathrm{H}, \mathrm{s})$, and $11.11(1 \mathrm{H}, \mathrm{s}) ;{ }^{13} \mathrm{C}$ n.m.r. spectrum $\left(\mathrm{CDCl}_{3}\right): \delta$ (p.p.m.) 31.3, 32.6, 35.1, 36.6, 121.4, 137.2, 147.4, 150.8, and 202.7, from TMS as internal reference.

2,4,6-Tri-t-butylthiobenzaldehyde. - The thiobenzaldehyde was synthesized in a similar way from 2,4,6-tri-t-butylbromobenzene $(8.15 \mathrm{~g}, 25.1 \mathrm{mmol})$, $n$-butyllithium $(30.1 \mathrm{mmol})$, and O-ethylthioformate $(2.70 \mathrm{~g}, 30.0 \mathrm{mmol})$. In this case the crude product was purified by recrystallization from ethanol under nitrogen atmosphere to give purple crystals $(4.0 \mathrm{~g}$, yield $56 \%$ ), m.p. $146-147^{\circ} \mathrm{C}$, giving satisfactory elemental analyses for $\mathrm{C}, \mathrm{H}$ and $\mathrm{S}$; ${ }^{1} \mathrm{H}$ n.m.r. spectrum $\left(\mathrm{CCl}_{4}\right): \delta$ (p.p.m.) $1.30(9 \mathrm{H}, \mathrm{s}), 1.32(18 \mathrm{H}$, s), $7.22(2 \mathrm{H}, \mathrm{s})$, and $13.02(1 \mathrm{H}, \mathrm{s}) ;{ }^{13} \mathrm{C}$ n.m.r. 
spectrum $\left(\mathrm{CDCl}_{3}\right): \delta$ (p.p.m.) 31.3, 32.9, 34.8, 37.0, $121.8,145.1,145.6,149.5$, and 250.4 , from TMS as internal reference.

\section{Physical Measurements}

The electric dipole moments were determined in benzene solution at $30.00 \pm 0.02{ }^{\circ} \mathrm{C}$ by using the well-known Debye refractivity method. The total polarization of the solute, extrapolated to infinite dilution, was calculated from the experimental ratios [8],

$$
\alpha_{0}=\lim _{w \rightarrow 0}\left[\frac{\varepsilon-\varepsilon_{1}}{w}\right] \text { and } \beta=\frac{\sum\left(v-v_{1}\right)}{\sum w},
$$

where $w$ is the weight fraction of the solute, $\varepsilon$ and $v$ are the dielectric permittivity and specific volume of the solutions, respectively, and subscript one refers to the pure solvent as used, i.e. made up in the same way as the solutions. The $\alpha_{0}$ value was calculated from the linear function, $\alpha=\alpha_{0}+\alpha^{\prime} w$, obtained by least-squares analysis of the $\varepsilon(w)$ polynomial (quadratic) function.

The distortion polarization of the solute, $E^{P}+A^{P}$, was assumed to equal the molecular refraction for the sodium $D$ line $\left(R_{D}\right)$, calculated from $\sum\left(n^{2}-n_{1}^{2}\right) / \sum w$ and $\beta$ defined as above. The techniques used to determine the dielectric permittivity, specific volume and refraction index of the solutions (and solvent) are described elsewhere $[9,10]$.

For each solute, $w_{\max }$ (here reported to only three decimal places, although it is known to five or six decimal places), $\alpha_{0}, \beta$ (in $\mathrm{cm}^{3} \mathrm{~g}^{-1}$ ), $P_{2 \infty}$ and $R_{D}$ (both in $\mathrm{cm}^{3} \mathrm{~mol}^{-1}$ ), and $\mu$ in Debye units $\left(1 \mathrm{D}=3.3356 \times 10^{-30} \mathrm{C} \mathrm{m}\right)$ are given in Table 1 .

\section{Results and Discussion}

First let us consider 2,4,6-tri-t-butylbenzaldehyde, then 2,4,6-tri-t-butylthiobenzaldehyde.

(1) 2,4,6-Tri-t-butylbenzaldehyde exhibits a dipole moment in benzene markedly inferior to that of benzaldehyde and 2,4,6-trimethylbenzaldehyde, but close to the values of 2,4,6-tribromobenzaldehyde and aliphatic aldehydes (see Table 2).

In the overcrowded 2,4,6-tri- $t$-butylbenzaldehyde and 2,4,6-tribromobenzaldehyde, where a consider- able formyl-group rotation $(\varphi)$ is likely to occur, the mesomeric moment is much reduced compared to the value in benzaldehyde known to exist as coplanar [18], and 2,4,6-trimethylbenzaldehyde existing in a near-coplanar conformation $[19,2]$ with a $\varphi$-angle of only $22^{\circ}[1]$. In addition, the $\pi$-inductive effect of the formyl-group in aromatic benzaldehydes, which does not require coplanarity of the molecular skeleton, is to be rather small.

The $\pi$-electron diagram of benzaldehyde reflects both the mesomeric and $\pi$-inductive effect of the formyl group (Figure 1). The first effect brings about an additional negative $\pi$-charge of $0.115-$ $(1.000-0.918)=0.033 e$ at the oxygen atom, and the second effect a negative $\pi$-charge of $0.018 e$ at the substituted ring-carbon atom [20]. With the molecular structures of benzaldehyde [18] and

Table 1. Physical data from dipole moment determinations at $30.0{ }^{\circ} \mathrm{C}$ with benzene as solvent.

\begin{tabular}{lcccccc}
\hline Compound & $w_{\max }$ & $\alpha_{0}$ & $-\beta$ & $P_{2 \infty}$ & $R_{D}$ & $\mu$ \\
\hline $\begin{array}{l}\text { 2,4,6-Tri-t-butyl- } \\
\text { benzaldehyde }\end{array}$ & 0.025 & 2.72 & 0.129 & 224.6 & $87.5^{\mathrm{a}}$ & 2.61 \\
$\begin{array}{l}\text { 2,4,6-Tri-t-butyl- } \\
\text { thiobenzaldehyde }\end{array}$ & 0.016 & 1.78 & 0.104 & 188.4 & $96.0^{\mathrm{b}}$ & 2.14 \\
\hline
\end{tabular}

a From experiment; $87.78 \mathrm{~cm}^{3} \mathrm{~mol}^{-1}$ as calculated from the experimental refractions of tri- $t$-butylbenzene (83.16 [11]) and refraction increments of $\mathrm{C}-\mathrm{C}$ and $\mathrm{C}=\mathrm{O}$ bonds (1.296 and $3.32[12])$, and $89.12 \mathrm{~cm}^{3} \mathrm{~mol}^{-1}$ from the experimental refractions of tri-t-butylbenzene (83.16), benzaldehyde (32.14) and benzene (26.18).

b From experiment; $96.37 \mathrm{~cm}^{3} \mathrm{~mol}^{-1}$ calculated from 2,4,6-tri- $t$-butylbenzaldehyde (87.78) and the refraction increments of $\mathrm{C}=\mathrm{S}$ and $\mathrm{C}=\mathrm{O}$ bonds (11.91 and 3.32 [12]).

Table 2. Experimental dipole moments of aldehydes and thioaldehydes in benzene (Debye units).

\begin{tabular}{llll}
\hline Aldehyde & $\mu$ & Thioaldehyde & $\mu$ \\
\hline Alcanal & $2.58^{\mathrm{a}}$ & Methanethial & $2.19^{\mathrm{b}}$ \\
$\begin{array}{l}\text { 2,4,6-Tri- } t \text {-bromo- } \\
\text { benzaldehyde }\end{array}$ & $2.53[14]$ & & \\
$\begin{array}{l}\text { 2,4,6-Tri- } t \text {-butyl- } \\
\text { benzaldehyde }\end{array}$ & 2.61 & $\begin{array}{l}\text { 2,4,6-Tri-t } t \text {-butyl- } \\
\text { thiobenzaldehyde }\end{array}$ & 2.14 \\
$\begin{array}{l}\text { 2,4,6-Trimethyl- } \\
\text { benzaldehyde }\end{array}$ & $2.96[15]$ & & \\
Benzaldehyde & $2.99[16]$ & Thiobenzaldehyde & $2.8^{\mathrm{c}}$ \\
\hline
\end{tabular}

a Average value from acetaldehyde (2.51), propionaldehyde $(2.56$ or 2.58$), n$-butyraldehyde $(2.57), i$-butyraldehyde (2.58), $n$-valeraldehyde (2.57), $i$-valeraldehyde (2.60) and $\alpha$-ethylcaproaldehyde (2.64) [13].

b Calculated from the value in the gaseous phase $(2.33$, [17]), see text.

c Estimated, see text. 


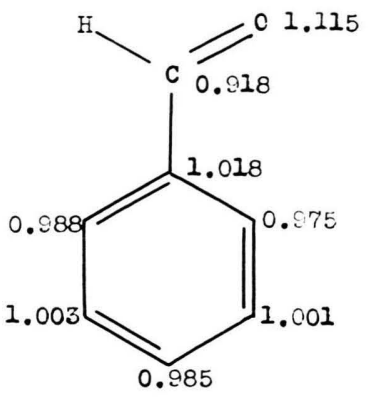

Fig. 1. Ab initio STO-3G $\pi$-electron densities in benzaldehyde.

acetophenone [21], and putting the positive poles of the mesomeric and $\pi$-inductive moments $\left(m_{0}\right.$ and $\left.\mu_{i}\right)$ at the ring centre, calculation yields $m_{0}=0.59 \mathrm{D}$ and $\mu_{i}=0.12 \mathrm{D}$.

That the mesomeric effect outweighs the $\pi$-inductive effect in benzaldehyde $(0.033 / 0.018=1.8)$ is supported by what follows. As referred to benzene 128.5 p.p.m., the para-carbon chemical shift of acetophenone (known to exist as coplanar in the crystalline phase [21]) is 4.4 p.p.m. [22], and it originates from acetyl mesomeric and $\pi$-inductive effects. For twisted 2,6-dimethylacetophenone, characterized by an acetyl-group rotational angle of $55^{\circ}$ [10], the para-carbon chemical shift (128.65 p.p.m. [23]) differs only by 0.55 p.p.m. from the value (128.10 p.p.m. [24]) of the para-carbon of meta-xylene and should mainly be ascribed to the $\pi$ inductive effect of acetyl, which does not require coplanarity of the molecular system. Accordingly, in coplanar acetophenone the mesomeric effect is responsible for ca. 4.0 p.p.m. and the $\pi$-inductive effect for only 0.4 p.p.m.

To obtain a significant value for the mesomeric moment in coplanar benzaldehyde $\left(m_{0}\right)$ and $\varphi$ twisted 2,4,6-tri- $t$-butylbenzaldehyde $(m)$, knowledge of the so-called benzaldehyde primary moment $\left(\boldsymbol{M}_{0}\right)$, which refers to a hypothetic molecule with no mesomeric moment, is needed. Clearly the dipole moment of 2,4,6-trimethylbenzaldehyde (2.96 D) can not serve as a measure of $\boldsymbol{M}_{0}$ since the molecule exists in a near-coplanar conformation (vide supra). That of 2,4,6-tribromobenzaldehyde fits much better because of the following. Its dipole moment $(2.53 \mathrm{D})$ is somewhat inferior to that of aliphatic aldehydes (Table 2). Strong repulsion between the $\mathrm{C}-\mathrm{Br}$ and $\mathrm{C}=\mathrm{O}$ dipoles compels the formyl-group to rotate considerably: 2-bromobenzaldehyde exists in a coplanar s-trans conformation [25-27]. The bromine atoms, in causing a positive $\pi$-charge at the formyl-substituted ring-carbon atom (the $\sigma_{p}$ bromine Hammett substitution constant of bromobenzene is +0.232 [28]), tend to reduce the formyl mesomeric effect (if any). It then follows that an orthogonal model can be retained for 2,4,6tribromobenzaldehyde.

Assuming the benzaldehyde mesomeric moment $\left(\boldsymbol{m}_{0}\right)$ directed from the ring geometric centre to the oxygen atom, that is at $16^{\circ}$ to the $\mathrm{C}_{\mathrm{ar}}-\mathrm{C}$ bond axis (from the actual structures of benzaldehyde [18] and acetophenone [21]), vector triangulation of $\boldsymbol{M}_{0}$ in terms of $\boldsymbol{\mu}(\mathrm{Ph}-\mathrm{CHO})\left(2.99 \mathrm{D}\right.$ at $34^{\circ}$ to the $\mathrm{Ph}-\mathrm{C}$ bond axis [16]) and $\boldsymbol{m}_{0}$ yields $m_{0}(\mathrm{Ph}-\mathrm{CHO})=0.49 \mathrm{D}$ (see [10] for details of calculations)*. Similarly, vector triangulation of the dipole moment of 2,4,6tri- $t$-butylbenzaldehyde $(2.61 \mathrm{D})$ in terms of $\boldsymbol{\mu}(\mathrm{Ph}-\mathrm{CHO})$ and $\Delta \boldsymbol{m}=\boldsymbol{m}_{0}-\boldsymbol{m}$ leads to $\Delta m=$ $0.405 \mathrm{D}$, and to $m=0.085 \mathrm{D}$ only in twisted $2,4,6$-tri$t$-butylbenzaldehyde.

Assuming $m=m_{0} \cdot \cos ^{2} \varphi$ (see [29] and [30]) leads to a $\varphi$-angle of $65^{\circ}$ in 2,4,6-tri- $t$-butylbenzaldehyde, a value which compares well with that $\left(68^{\circ}\right)$ drawn from ${ }^{1} \mathrm{H}$ n.m.r. spectroscopy [5]. Because of the large formyl-group rotation in 2,4,6-tri-t-butylbenzaldehyde $\left(\varphi=68^{\circ}[5]\right)$, the increase in the $m$-value due to the $\pi$-negative charge induced at the formylsubstituted ring-carbon atom $\left(\sigma_{p}(t-\mathrm{Bu})=-0.197\right.$ in $t$-butylbenzene [28]) can be ignored, the more so as the formyl-group rotational barriers in coplanar $p$ methylbenzaldehyde and benzaldehyde (34.3 and $32 \mathrm{~kJ} \mathrm{~mol}^{-1}$ [31]) are close. Note also that $t$-butyl and bromine substituents have a reverse effect on the dipole moments of both orthogonal 2,4,6-tri-tbutyl- and 2,4,6-tribromo-acetophenone (2.52 [32] and $2.58 \mathrm{D}$ [14]), and on those of twisted 2,4,6-tri$t$-butylbenzaldehyde and orthogonal 2,4,6-tribromobenzaldehyde ( 2.61 and $2.53 \mathrm{D})$, showing that the twisting factor plays a major role for benzaldehydes.

It has been observed that the carbonyl-carbon n.m.r. chemical shift of acetophenone, 2,4,6-trimethyl- and 2,4,6-tri-i-propylacetophenone gradually augments with the twisting angle increasing [33], and such can be extended to the more crowded

* In [10], p. 174 , line 16 should read "where $\tau$ is the angle that the vector $\boldsymbol{m}_{0}$ makes with the $\mathrm{C}_{\mathrm{ar}}-\mathrm{C}$ bond axis". 
Table 3. Carbon-13 carbonyl-carbon chemical shifts of aromatic aldehydes and ketones, in $\mathrm{CDCl}_{3}$.

\begin{tabular}{|c|c|c|c|}
\hline Aldehyde & $\delta^{\mathrm{a}}$ & Ketone & $\delta^{\mathrm{a}}$ \\
\hline \multirow{6}{*}{$\begin{array}{l}\text { Benzaldehyde } \\
2,4,6 \text {-Trimethyl- } \\
\text { benzaldehyde } \\
2,4,6 \text {-Triethyl- } \\
\text { benzaldehyde } \\
2,4,6 \text {-Tri- } i \text {-propyl- } \\
\text { benzaldehyde } \\
\text { 2,4,6-Trineopentyl- } \\
\text { benzaldehyde } \\
\text { 2,4,6-Tri- } t \text {-butyl- } \\
\text { benzaldehyde }\end{array}$} & $192.1[4]$ & \multirow{3}{*}{$\begin{array}{l}\text { Acetophenone } \\
\text { 2,4,6-Trimethyl- } \\
\text { acetophenone }\end{array}$} & \multirow{3}{*}{$\begin{array}{l}198.2[23] \\
208.5[23]\end{array}$} \\
\hline & $192.5[4]$ & & \\
\hline & $192.3[4]$ & & \\
\hline & 194.7 [4] & \multirow[t]{2}{*}{$\begin{array}{l}\text { 2,4,6-Tri-i-propyl- } \\
\text { acetophenone }\end{array}$} & \multirow[t]{2}{*}{$208.8[33]^{t}$} \\
\hline & $194.4[4]$ & & \\
\hline & 202.7 [6] & $\begin{array}{l}2,4,6 \text {-Tri- } t \text {-butyl- } \\
\text { acetophenone }\end{array}$ & $211.6[32]$ \\
\hline
\end{tabular}

a In p.p.m., from TMS. - b In 1,4-Dioxane.

2,4,6-tri-t-butylacetophenone (Table 3). Also for benzaldehydes, the chemical shift increment augments on passing from benzaldehyde $(\Delta \delta=0.0)$, to 2,4,6-trimethylbenzaldehyde $(\Delta \delta=2.4), 2,4,6$-tri- $i$ propylbenzaldehyde $(\Delta \delta=2.6), 2,4,6$-trineopentylbenzaldehyde $(\Delta \delta=2.3)$ and 2,4,6-tri-t-butylbenzaldehyde $(\Delta \delta=10.6)$. Interestingly, for 2,4,6-tri$t$-butylbenzaldehyde the $\Delta \delta$ value (10.6) is close to that observed for 2,4,6-trimethylacetophenone $(\Delta \delta=10.3)$ characterized by a twisting angle of about $55^{\circ}$ [10]. Note that the effect of alkyls on ring-carbonyl conjugation in the quoted 2,4,6-trialkyl-benzaldehydes and -acetophenones, which is certainly much reduced by acyl-group rotation, should be similar since the para-carbon shifts (related to the $\pi$-electron density [34]), as referred to benzene 128.5 p.p.m., are close for toluene, ethyland $t$-butyl-benzene $(-2.9,-2.6$ and -2.9 p.p.m. in benzene [22]), and neopentylbenzene (-2.7 p.p.m. in cyclohexane [22]).

(2) The electric dipole moment of 2,4,6-tri$t$-butylthiobenzaldehyde in benzene solution $(2.14 \mathrm{D})$ can not be compared to that of aromatic thiobenzaldehyde and aliphatic thioacetaldehyde (Table 2). Thiobenzaldehyde is too unstable for its dipole moment being measured even in the gaseous phase [35], and thioacetaldehyde was only examined as vapour: $\mu_{g}=2.33 \mathrm{D}$ by microwave spectroscopy [17].
The dipole moment of thiobenzaldehyde can be predicted to be $2.8 \mathrm{D}$ as follows. First, benzaldehyde and acetophenone possess close dipole moments in benzene (2.99 [16] and 2.95 D [36]); second, ringclosed 2,2-dimethylindan-1-thione and 2,2-dimethylindan-1-one exhibit values of 3.19 and $3.35 \mathrm{D}$ in the same solvent [37].

As a benzene solute, the thioacetaldehyde dipole moment can be calculated from the gaseous value (2.33 D) by means of Müller's equation for the solvent effect [38],

$$
\mu_{b}=\mu_{g} \cdot\left[1-0.038\left(\varepsilon_{b}-1\right)^{2}\right],
$$

where $\varepsilon_{b}=2.2642$ is the benzene dielectric permittivity. This leads to $\mu_{b}=0.94 \times \mu_{g}=2.19 \mathrm{D}$. Note that the experimental $\left(\mu_{b} / \mu_{g}\right)$ ratios are close to 0.94 for acetaldehyde $(2.51 / 2.68=0.94$ [13]), propionaldehyde $(2.56 / 2.75=0.93$ [13] $)$, and also benzaldehyde $(2.99[16] / 3.21[18]=0.93)$.

As compared to thioacetaldehyde in benzene $(2.19 \mathrm{D})$, the low value found for 2,4,6-tri-t-butylthiobenzaldehyde $(2.14 \mathrm{D})$ clearly supports a strongly twisted conformation in solution, with a twisting angle much greater than that of 2,4,6-tri- $t$-butylbenzaldehyde $\left(65^{\circ}\right)$ since the sulphur molecule is more overcrowded (when coplanar) than the oxygen analogue*. An orthogonal structure, with a $\varphi$-angle of $89.1^{\circ}$, is observed for 2,4,6-tri-t-butylthiobenzaldehyde in the crystalline phase [7].

Thus, greater hindrance in the sulphur compound outweighs the conjugation effect of thioformyl to be more pronounced. The thiocarbonyl mesomeric effect is known to be much greater than that of carbonyl in coplanar thiocarbonyl unsaturated compounds [40] and N,N'-dimethylimidazolidin-2thione [41]. A comparison of the dipole moments of thiobenzaldehyde (2.8 D) and 2,4,6-tri-t-butylthiobenzaldehyde (taken as $\boldsymbol{M}_{0}$ ) suggests $m \sim 0.8 \mathrm{D}$ in the former, to be compared with the value for benzaldehyde (0.49 D).

* The sulphur and oxygen van der Waals radii are 1.85 and $1.40 \AA$, respectively [39], and the $\mathrm{C}=\mathrm{S}$ and $\mathrm{C}=\mathrm{O}$ distances 1.596 [7] and $1.216 \AA$ [21], while the $\mathrm{C}_{\mathrm{ar}} \mathrm{CS}$ and $\mathrm{C}_{\mathrm{ar}} \mathrm{CO}$ angles differ little (127.1 [7] and $\left.123.4^{\circ}[18]\right)$. 
[1] E. A. Braude and F. Sondheimer, J. Chem. Soc. 1955, 3754.

[2] M. J. Aroney, M. G. Corfield, and R. J. W. Le Fèvre, J. Chem. Soc. 1964, 648

[3] A. Lakshmi, S. Walker, M. A. Weir, and J. H. Calderwood, J. Phys. Chem. 78, 1091 (1982).

[4] S. Andersson, R. E. Carter, and T. Drakenberg, Acta Chem. Scand. B 38, 579 (1984).

[5] W. A. Gibbons, quoted by W. A. Gibbons and V. M. S. Gil, Mol. Phys. 9, 167 (1965).

[6] R. Okazaki, A. Ishii, N. Fukuda, H. Oyama, and N. Inamoto, J. Chem. Soc. Chem. Commun. 1982, 1187.

[7] F. Iwasaki, private communication.

[8] I. F. Halverstadt and W. D. Kumler, J. Amer. Chem. Soc. 64, 2988 (1942).

[9] H. Lumbroso, D. M. Bertin, and P. Cagniant, Bull. Soc. Chim. Fr. 1970, 1720.

[10] H. Lumbroso, Ch. Liégeois, G. Goethals, and R. Uzan, Z. Phys. Chem. N.F., München 138, 167 (1983).

[11] M. J. Aroney and St. J. Pratten, J. Chem. Soc. Faraday Trans. I, 80, 1201 (1984).

[12] A. I. Vogel, W. T. Cresswell, G. H. Jeffery, and J. Leicester, J. Chem. Soc. 1952, 514.

[13] A. L. McClellan, Tables of Experimental Dipole Moments, Vol. I, W. H. Freeman \& Co., San Francisco 1963; Vol. II, Rahara Enterprises, El Cerrito, Calif. (USA) 1974.

[14] J. W. Smith, J. Chem. Soc. 1957, 4050.

[15] R. G. Kadesh and S. W. Weller, J. Amer. Chem. Soc. 63, 1310 (1941).

[16] H. Lumbroso and C. G. Andrieu, Bull. Soc. Chim. Fr. I, 1973, 1575 .

[17] H. W. Kroto and B. M. Landsberg, J. Mol. Spectrosc. 62, 346 (1976).

[18] Y. Kawashima and K. Kozima, Bull. Chem. Soc. Japan 47, 2879 (1974)

[19] M. J. Murray, F. F. Cleveland, and R. H. Saunders, J. Amer. Chem. Soc. 64, 1181 (1942).

[20] H. Lumbroso, Ch. Liégeois, G. C. Pappalardo, and V. Librando, J. Mol. Struct. 62, 195 (1980).

[21] Y. Tanimoto, H. Kobayashi, S. Nagakura, and Y. Saito, Acta Crystallogr. B 29, 1822 (1973).

[22] D. F. Ewing, Org. Magn. Reson. 12, 499 (1979), and references cited therein.
[23] G. Goethals, Thesis, Amiens (France), 1983; G. Goethals, R. Uzan, L. Nadjo, and J.-P. Doucet, J. Chem. Soc. Perkin Trans. II, 1982, 885.

[24] G. Goethals, private communication.

[25] W. B. Smith, D. L. Deavenport, and A. M. Ihrig, J. Amer. Chem. Soc. 94, 1959 (1982)

[26] C. T. Aw, H. H. Huang, and E. L. K. Tan, J. Chem. Soc. Perkin Trans. II, 1972, 1638.

[27] E. A. W. Bruce, G. L. D. Ritchie, and A. J. Williams, Austral. J. Chem. 27, 1809 (1974).

[28] C. G. Swain and E. C. Lupton, Jr., J. Amer. Chem. Soc. 90, 4328 (1968).

[29] E. G. McRae and L. Goodman, J. Chem. Phys. 29, 334 (1958).

[30] H. Lumbroso and Ch. Liégeois, Z. Phys. Chem. N.F., München 134, 149 (1983).

[31] R. Benassi, L. Schenetti, and F. Taddei, J. Chem. Soc. Perkin Trans. II, 1979, 545, and references cited therein.

[32] J. Koudelka, D. Saman, and O. Exner, Coll. Czechoslov. Chem. Commun. 50, 208 (1985).

[33] K. S. Dhami and J. B. Stothers, Canad. J. Chem. 43, 479 (1965).

[34] G. J. Martin, M. L. Martin, and S. Odiot, Org. Magn. Reson. 7,2 (1975).

[35] H. Bock, T. Hirabayashi, and S. Mohmand, Chem. Ber. 115, 492 (1982).

[36] S. Sorriso, G. Piazza, and A. Foffani, J. Chem. Soc. B 1971, 805 .

[37] H. Lumbroso, Ch. Liégeois, and C. G. Andrieu, Z. Naturforsch. 40 a (1985), in press.

[38] F. H. Müller, Physik. Z. 36, 371 (1935); 38, 283 (1937); see C. P. Smyth, Dielectric Behaviour and Molecular Structure, McGraw-Hill, New York 1955, pp. 39 and 40.

[39] L. Pauling, The Nature of the Chemical Bond and the Structure of Molecules and Crystals, Cornell University Press, Ithaca, New York, 2nd Edition, 1948, p. 189.

[40] C. G. Andrieu, P. Metzner, D. Debruyne, D. M. Bertin, and H. Lumbroso, J. Mol. Struct. 39, 263 (1977).

[41] H. Lumbroso, Ch. Liégeois, F. A. Devillanova, and G. Verani, J. Mol. Struct. 77, 239 (1981). 